\title{
Long-Term Results of Thermal Ablation of Benign Thyroid Nodules: A Systematic Review and Meta-Analysis
}

\author{
Se Jin Cho ${ }^{1,2}$, Jung Hwan Baek ${ }^{1}$, Sae Rom Chung ${ }^{1}$, Young Jun Choi ${ }^{1}$, Jeong Hyun Lee ${ }^{1}$ \\ ${ }^{1}$ Department of Radiology and Research Institute of Radiology, Asan Medical Center, University of Ulsan College of Medicine, \\ Seoul; ${ }^{2}$ Department of Radiology, Seoul National University Bundang Hospital, Seoul National University College of Medicine, \\ Seongnam, Korea
}

Background: Ultrasound-guided thermal ablations have become one of the main options for treating benign thyroid nodules. To determine efficacy of thermal ablation of benign thyroid nodules, we performed a meta-analysis of studies with long-term follow-up of more than 3 years.

Methods: Databases were searched for studies published up to August 25, 2019, reporting patients with benign thyroid nodules treated with thermal ablation and with follow-up data of more than 3 years. Data extraction and quality assessment were performed according to PRISMA guidelines. The analysis yielded serial volume reduction rates (VRRs) of ablated nodules for up to 3 years or more, and adverse effect of ablation during follow-up. Radiofrequency ablation (RFA) and laser ablation (LA) were compared in a subgroup analysis.

Results: The pooled VRRs for ablated nodules showed rapid volume reduction before 12 months, a plateau from 12 to 36 months, and more volume reduction appearing after 36 months, demonstrating long-term maintenance of treatment efficacy. Thermal ablation had an acceptable complication rate of 3.8\%. Moreover, patients undergoing nodule ablation showed no unexpected delayed complications during the follow-up period. In the subgroup analysis, RFA was shown to be superior to LA in terms of the pooled VRR and the number of patients who underwent delayed surgery.

Conclusion: Thermal ablations are safe and effective methods for treating benign thyroid nodules, as shown by a long follow-up analysis of more than 3 years. In addition, RFA showed superior VRRs compared with LA for the treatment of benign thyroid nodules, with less regrowth and less delayed surgery.

Keywords: Radio frequency ablation; Thyroid adenoma; Meta-analysis

\section{INTRODUCTION}

Ultrasound-guided thermal ablations have become one of the main options for treating benign thyroid nodules, solving cosmetic problems and compressive symptoms [1,2]. Although thermal ablation has shown favorable efficacy in volume reduc- tion [3-14], a few studies with long follow-up periods showed regrowth of treated nodules 2 to 3 years after ablation $[6,8,9,13$, 14]. To clarify the frequency of regrowth after thermal ablation, a meta-analysis of studies with long-term follow-up of more than 2 to 3 years is required.

Radiofrequency ablation (RFA) and laser ablation (LA) are
Received: 29 January 2020, Revised: 3 April 2020, Accepted: 14 April 2020 Corresponding author: Jung Hwan Baek

Department of Radiology and Research Institute of Radiology, Asan Medical Center, University of Ulsan College of Medicine, 88 Olympic-ro 43-gil, Songpa-gu, Seoul 05505, Korea

Tel: +82-2-3010-4348, Fax: +82-2-476-0090, E-mail: radbaek@naver.com
Copyright $\odot 2020$ Korean Endocrine Society

This is an Open Access article distributed under the terms of the Creative Commons Attribution Non-Commercial License (https://creativecommons.org/ licenses/by-nc/4.0/) which permits unrestricted non-commercial use, distribution, and reproduction in any medium, provided the original work is properly cited. 
the two main ablation options for treating benign thyroid nodules [3-14]. A previous meta-analysis compared the short-term results (6 to 12 months) of RFA and LA, and demonstrated RFA to have superior efficacy to LA in the treatment of benign thyroid nodules in terms of volume reduction and safety [15]. However, the results revealed only limited information with which to compare the long-term differences in efficacy of each of the thermal ablation techniques.

Therefore, we systematically reviewed the literature and performed a meta-analysis on the long-term efficacy of thermal ablation for benign thyroid nodules. In addition, we performed a subgroup analysis comparing different ablation methods.

\section{METHODS}

This systematic review and meta-analysis was performed according to the Preferred Reporting Items for Systematic Reviews and Meta-Analyses (PRISMA) guidelines [16].

\section{Literature search}

A search of MEDLINE and EMBASE databases was performed to find original literature reporting patients with benign thyroid nodules treated with thermal ablation and with follow-up data for more than 3 years. The following search terms were used: ([thyroid nodule] OR [thyroid tumor] OR [thyroid]) AND ([ablation] OR [percutaneous ablation] OR [thermal ablation]) AND ([radiofrequency] OR [radio-frequency] OR [laser] OR [interstitial photocoagulation] OR [microwave] OR [microwave coagulation] OR [HIFU] OR [High-intensity focused ultrasound]). No beginning search date was set, with the literature search being updated until August 25, 2019. The search was limited to English-language publications. The bibliographies of relevant articles were searched to identify any other appropriate articles.

\section{Inclusion criteria}

Studies satisfying the following criteria were included: (1) patients with a benign thyroid nodule treated with thermal ablation; and (2) follow-up data for more than 3 years after ablation.

\section{Exclusion criteria}

Studies or subsets of studies were excluded if any of the following criteria were met: (1) case reports or case series including fewer than 20 patients; (2) letters, editorials, conference abstracts, systematic reviews or meta-analyses, consensus statements, guidelines, and review articles; (3) articles not focusing on the current topic; (4) articles with, or with suspicion of, over- lapping populations; (5) articles without follow-up data for more than 3 years after ablation; and (6) articles without reference standards based on cytopathological or histopathological tests.

Two radiologists, S.J.C. and J.H.B., with 5 and 25 years of experience in thyroid imaging, respectively, independently performed the literature search and selection.

\section{Data extraction}

The following data were extracted using standardized forms according to the PRISMA guidelines [16]: (1) characteristics of the article, including ablation methods, institution, country of origin, authors, year of publication, duration of patient recruitment, number of patients, mean patient age, male to female ratio, and study design (prospective or retrospective); (2) details of the included nodules [17], including the total number of ablated nodules and the criteria for ablation (summary of inclusion and exclusion criteria); (3) details of the thermal ablation, including ablation methods and devices, power output, applicator, mean ablation time, techniques used (local anesthesia, transisthmic approach [18], hydro-dissection [18], moving-shot technique [18,19], and pull-back coagulation [8]); (4) results of ablation and details of follow-up, including mean follow-up duration, mean nodule volume, serial changes in the post-treatment volume reduction rate (VRR) of the index nodule (before, 6,12 , 24, and 36-month data and last follow-up, with VRR during follow-up calculated as: [initial nodular volume-final nodular volume] $\times 100$ )/initial nodular volume; complications associated with ablation; and number of surgical procedures performed during follow-up after ablation.

Complications were evaluated using the reporting standards of the Society of Interventional Radiology [20]. Major complications were defined as adverse events associated with substantial morbidity or disability, an increased level of care, hospital admission, or substantial prolongation of hospital stay. All other complications were regarded as minor complications, and side effects were defined as unintended consequences that did not require therapy or medical treatment, as well as undesired consequences of the procedure according to previous studies $[21,22]$. In terms of voice change, a duration exceeding 1 month was considered a major complication, and a duration less than 1 month was considered a minor complication. If the duration was not presented, it was considered a major complication. However, occurrences immediately following ablation, including transient voice change, minimal or asymptomatic hematoma, bleeding, parenchymal edema, and tolerable mild pain or 
discomfort not requiring medication, were regarded as neither complications nor side effects. Early complications were defined as those occurring within 30 days after ablation, and delayed complications as those occurring after 30 days.

\section{Quality assessment}

Two authors (S.J.C. and J.H.B.) independently performed data extraction and quality assessment using the risk of bias for nonrandomized studies (RoBANS) tool for nonrandomized controlled trials [23].

\section{Data synthesis and analyses}

The primary outcome of the current systematic review and metaanalysis was the serial VRRs of ablated nodules over 3 years or more. A secondary outcome was a description of the adverse effects of ablation, including the rates of complications and surgery during follow-up after ablation. The pooled proportions were calculated using an inverse-variance weighting model [2426]. Random effects meta-analysis of proportions was utilized to calculate the overall proportions. Study heterogeneity was evaluated using Higgins inconsistency index $\left(I^{2}\right)$, with substantial heterogeneity being indicated by an $I^{2}$ value greater than $50 \%$ [27]. In addition, subgroup analysis was performed according to the different ablation methods. All statistical analyses were conducted by one author (S.J.C., with 2 years of experience in conducting systematic reviews and meta-analysis), using the "meta" package in R version 3.6.1 (http://www.r-project.org/).

\section{RESULTS}

\section{Literature search}

The article selection process is described in Fig. 1. The initial systematic literature search identified 1,452 articles. After removing 616 duplicates, screening of the remaining 836 titles and abstracts yielded 18 potentially eligible articles. Searches of the bibliographies of these articles identified one additional article [3]. The full text reviews of the 19 provisionally eligible articles found that four articles did not contain follow-up data of more than 3 years' duration [28-31], two articles included populations that overlapped or were suspected of overlapping [32,33], and one article was a case series [34]; these seven articles were excluded. Finally, 12 (five for RFA and seven for LA) studies were included in the qualitative synthesis in the current systematic review [3-14]. Other ablation studies such as microwave ablation or high-intensity focused ultrasound ablation did not meet our inclusion criteria.

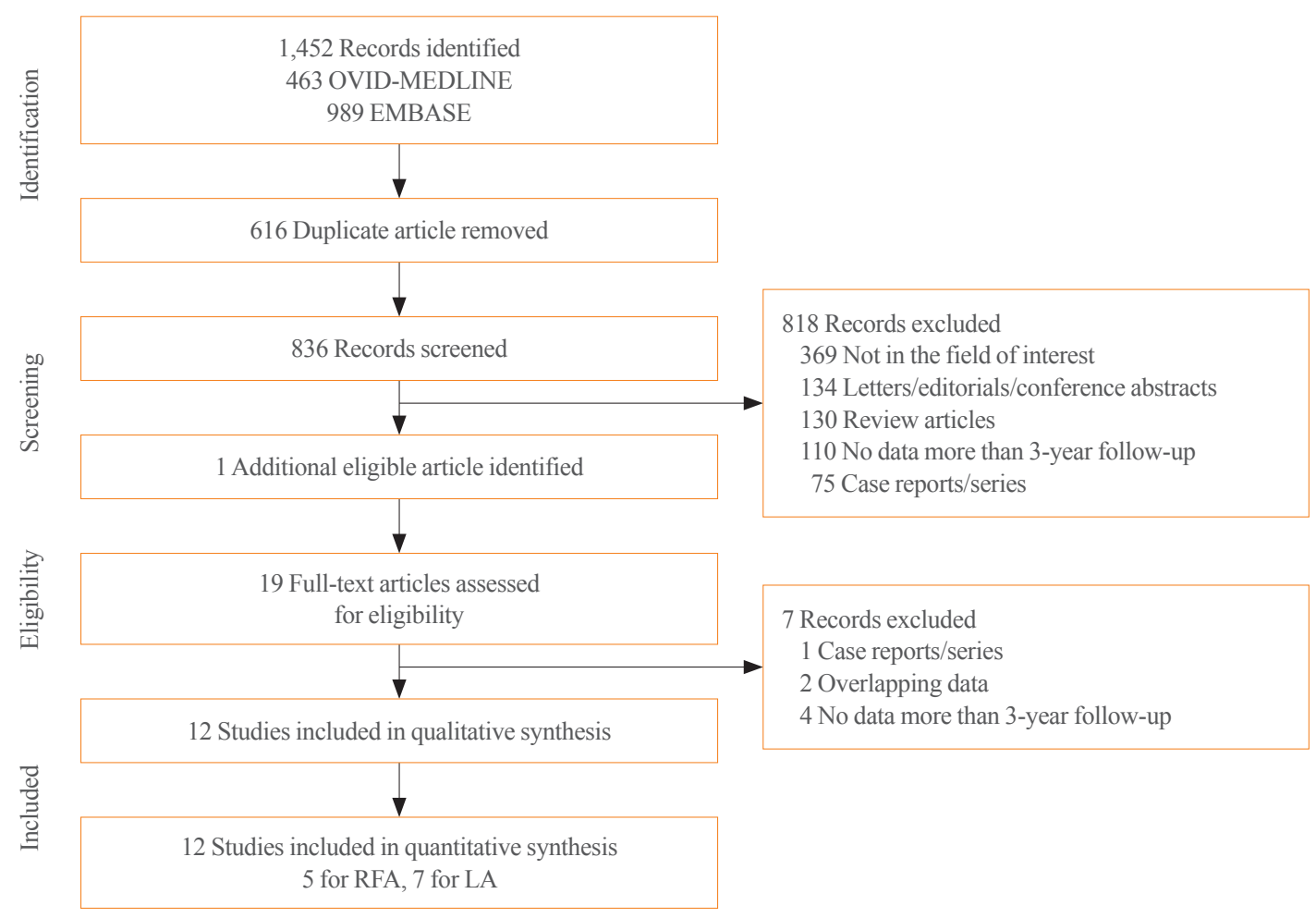

Fig. 1. Flow diagram of the study selection process. RFA, radiofrequency ablation; LA, laser ablation. 


\section{Characteristics of the included studies}

Table 1 shows the detailed characteristics of the 12 studies, including five on RFA [10-14] and seven on LA [3-9]. Two studies (one RFA and one LA study) were multicenter designs $[8,12]$, but the others were from single centers. A total of 1,223 nodules from 1,208 patients were enrolled. The 695 nodules from 680 patients who underwent RFA and the 528 nodules from 528 patients who underwent LA were evaluated after ablation. The sizes of the study populations ranged from 24 to 276 patients, with the patients having a mean age of 37.9 to 66 years. Ten studies were retrospective in design [3-7,9-11,13,14], whereas the two others were prospective $[8,12]$. All studies commonly included nodules verified as being benign by tissue confirmation; however, the detailed inclusion and exclusion criteria were similar but slightly different across the studies. Nine studies included symptomatic or cosmetic problems in the inclusion criteria $[3,4,6,7,9,10,12-14]$, whereas the other three did not mention the presence of such problems $[5,8,11]$. Only one study involved the treatment of toxic or hot nodules [5]. Among the seven studies describing the inclusion criteria in terms of nodule components [3,4,8-12], six studies enrolled solid or predominantly solid nodules [3,4,8-11], whereas the other study enrolled both predominantly solid (248 of 278) and predominantly cystic nodules (28 of 276) [12]. Four studies included nodule size in the inclusion criteria $[4,8,9,13]$. The other detailed criteria for ablation are described in Table 1.

\section{Characteristics of the ablation methods}

The detailed characteristics of each ablation method are presented in Table 2. All RFA studies used an internally cooled electrode with various sizes of active tips, whereas the LA studies used a 300 or $400 \mu \mathrm{m}$ laser fiber as an applicator. The mean ablation times ranged from 5 to 19.4 minutes, showing no tendency according to the type of ablation. One of five studies in the RFA group [11] and four of seven studies in the LA group performed a single ablation session for the nodules $[4,5,8,9]$. However, three of five studies in the RFA group [10,12,13], and three of seven studies in the LA group performed either a single or multiple sessions of ablation [3,6,7]. The mean number of ablation sessions ranged from one to 3.5 in the RFA group, and one to 1.2 in the LA group. In the RFA group, all studies commonly administered local anesthesia using $1 \%$ to $2 \%$ lidocaine, without sedation. In the LA group, one study performed ablation without local anesthesia or sedation [5], one study used sedation without local anesthesia [4], two studies used local anesthesia without sedation $[3,8]$, and the other three studies used both local anesthesia and sedation $[6,7,9]$. In terms of techniques, the studies in the RFA group commonly used a transisthmic approach and a moving-shot technique [10-14], while the studies in the LA group commonly used pull-back techniques [3-9].

\section{Results of ablation}

The pooled mean volume of the index nodules before ablation was $16.1 \mathrm{~mL}$, ranging from 8.2 to $36.3 \mathrm{~mL}$ (Table 3). The number of patients with a symptomatic or cosmetic problem, or their scores for these problems, the mean VRRs of the ablated lesions over the follow-up period, and the pooled proportions according to the meta-analysis, are listed in Table 3. The pooled VRRs at 6, 12, 24, 36 months, and last follow-up were 54.7\% (95\% confidence interval [CI], $47.5 \%$ to $61.8 \%), 62.8 \%(95 \% \mathrm{CI}, 53.3 \%$ to $71.4 \%$ ), $62.1 \%$ (95\% CI, $47.5 \%$ to $74.8 \%$ ), $62.7 \%$ (95\% CI, $49 \%$ to $74.6 \%$ ), and $76.9 \%$ (95\% CI, $54.9 \%$ to $90.1 \%$ ) (Supplemental Fig. S1). The overall effect estimate presented as diamond shape in the forest plot. Besides, the relatively symmetric distribution of included studies were shown in the funnel plot, respectively. Fig. 2 shows the trends in the pooled VRRs for ablated nodules in total, and separately for the RFA and LA groups. For the ablated nodules in total, the VRR plateaued from 12 to 36 months. Thereafter, a further volume reduction appeared after 36 months. The pooled proportions of overall, minor, and major complications were $3.8 \%$ (95\% CI, $1.6 \%$ to 9.1\%), $2.8 \%$ (95\% CI, $1.2 \%$ to $6.6 \%$ ), and $1.5 \%$ (95\% CI, $0.6 \%$ to $3.6 \%$ ), respectively. Moreover, the patients showed no unexpected delayed complications during the follow-up period. The pooled proportion of patients who underwent delayed surgery was $12.8 \%$ (95\% CI, $4.2 \%$ to $32.8 \%)$.

\section{Subgroup analysis}

The pooled mean index nodule volumes were $16.2 \mathrm{~mL}$ (range, 9.8 to 36.3 ) in the RFA group and $16.1 \mathrm{~mL}$ (range, 8.2 to 23.1 ) in the LA group (Table 3). The pooled VRRs at 6, 12, 24, 36 months, and last follow-up were $64.5 \%$ (95\% CI, 56.1\% to $72.1 \%$ ), $76.9 \%$ (95\% CI, 65\% to $85.7 \%$ ), $80.1 \%$ (95\% CI, $66.4 \%$ to $89.2 \%$ ), $80.3 \%$ (95\% CI, $66 \%$ to $89.5 \%$ ), and $92.2 \%$ (95\% CI, $71.9 \%$ to $98.2 \%$ ), respectively, in the RFA group, and $48.3 \%$ (95\% CI, $43.1 \%$ to $53.6 \%$ ), $52.3 \%$ (95\% CI, $46.1 \%$ to $58.5 \%$ ), $45.5 \%$ (33.1\% to $58.5 \%$ ), $45.9 \%$ (95\% CI, $35.3 \%$ to $57 \%$ ), and $43.3 \%$ (95\% CI, $28.9 \%$ to $59 \%$ ) in the LA group. Study heterogeneity was substantial in both RFA $\left(I^{2}=73.7 \%\right.$ to $95.9 \%)$ and LA groups $\left(I^{2}=76.2 \%\right.$ to $\left.81.9 \%\right)$. The VRR in the RFA group gradually increased up to $92.2 \%$ at the last follow- 


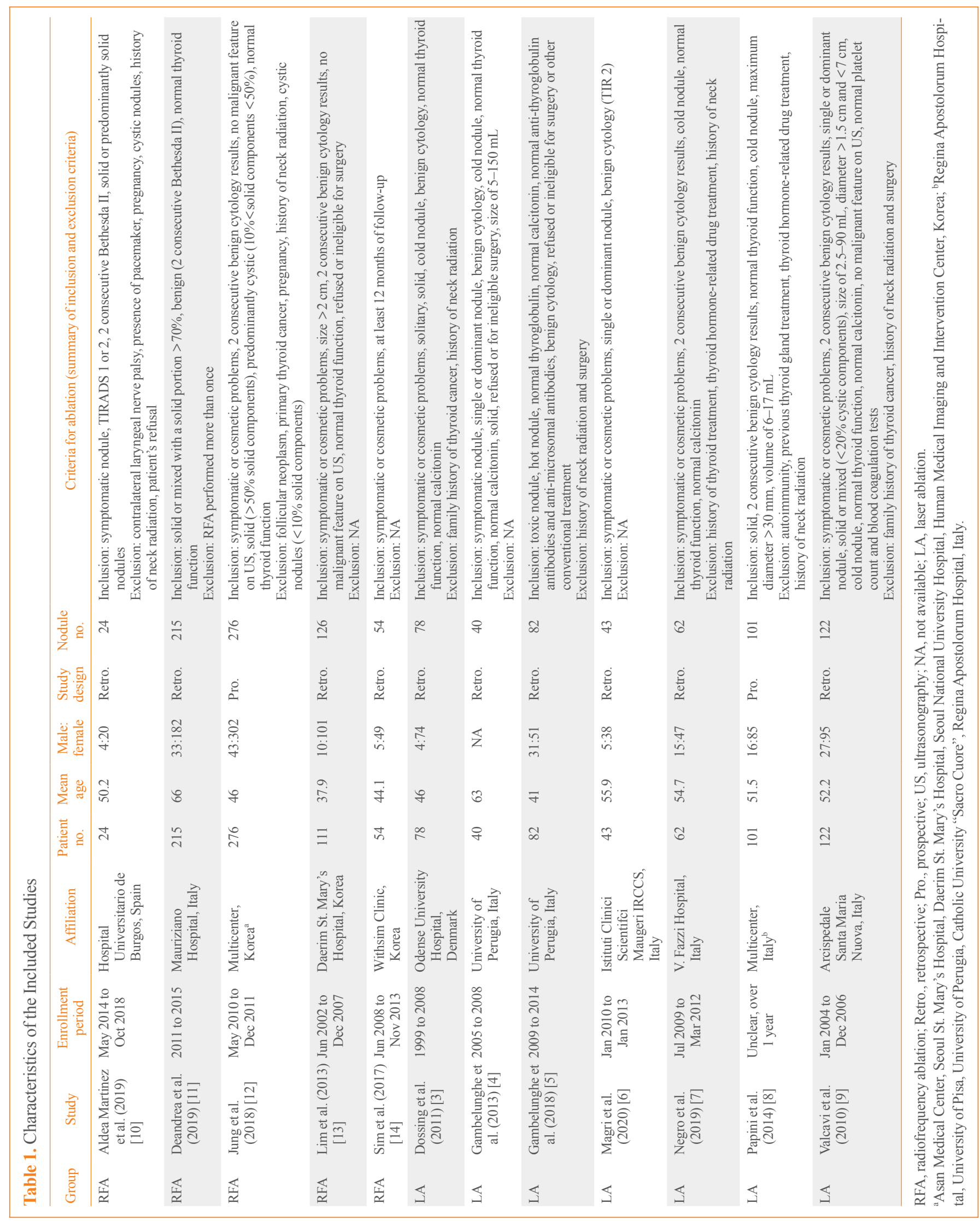




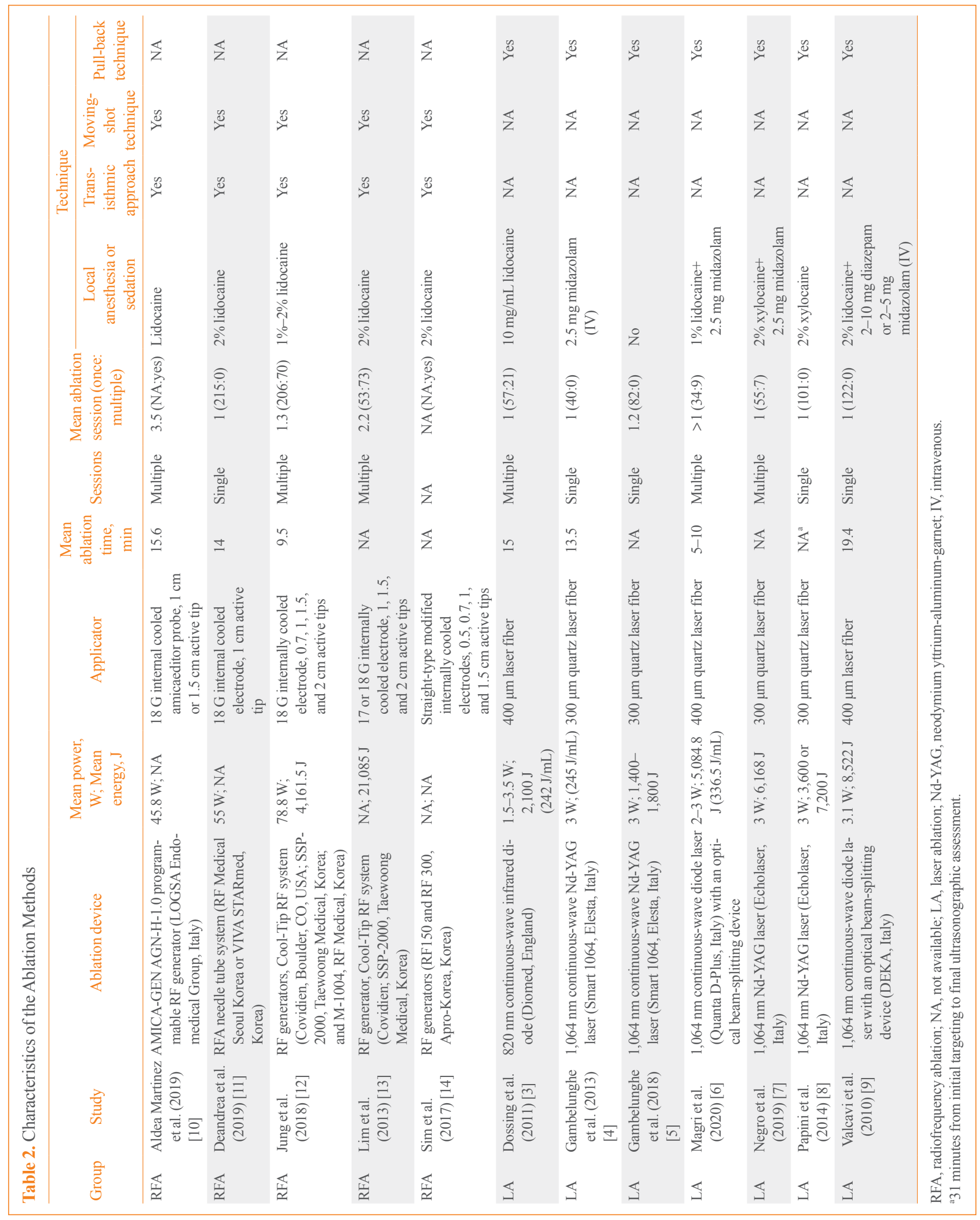




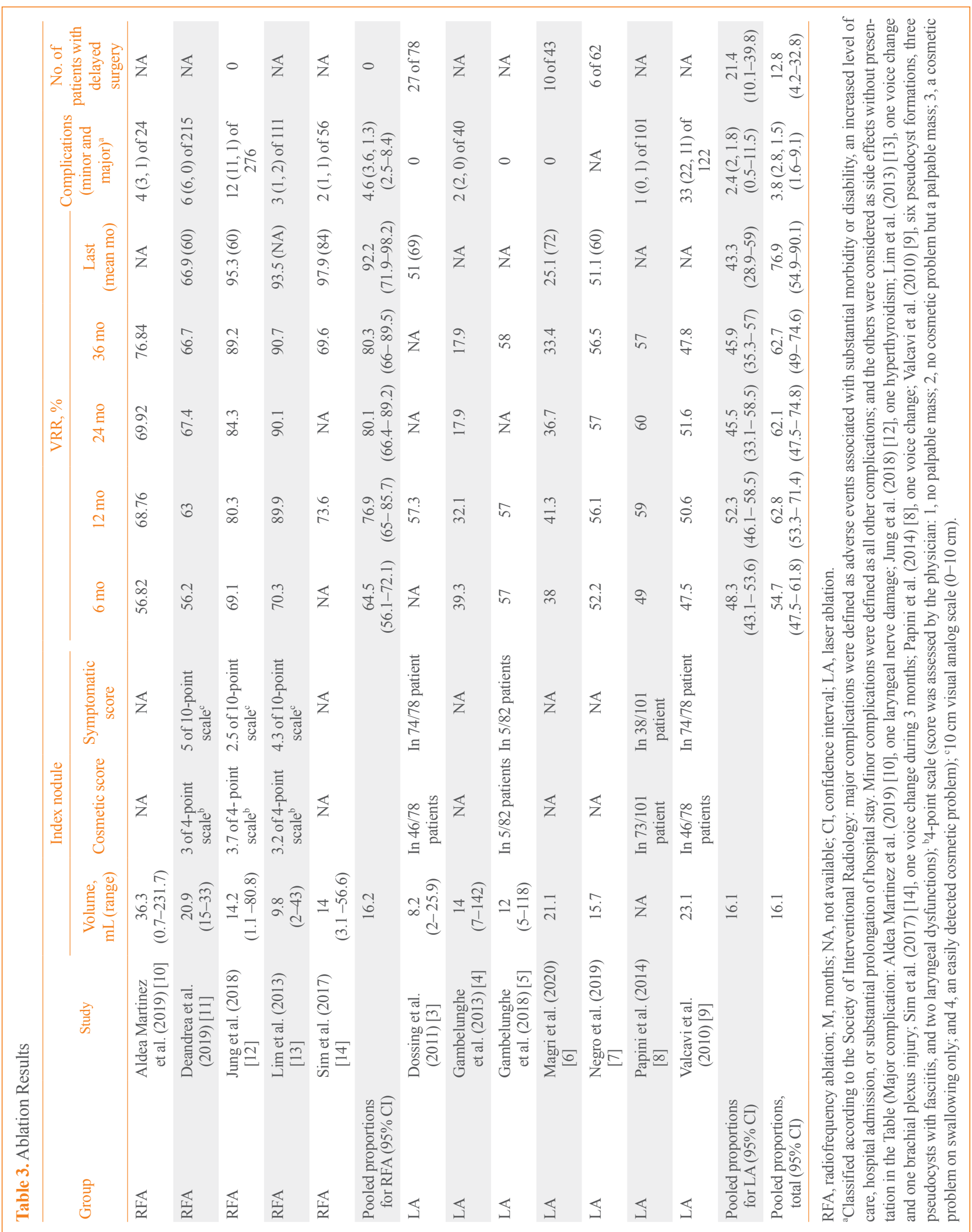


up, whereas the VRR in the LA group peaked at 12 months $(52.3 \%)$ and then showed a slight reduction during the later follow-up (43.3\%, at last follow-up) (Fig. 2). In terms of safety, the complication rates were $4.6 \%$ in the RFA group and $2.4 \%$ in the LA group, and the major complication rates were $1.3 \%$ in the RFA group and $1.8 \%$ in the LA group. In the RFA group, only one study reported on the rate of delayed surgery, with no patient having undergone it, whereas the pooled proportion of patients who underwent delayed surgery in the LA group was $21.4 \%$ (95\% CI, $10.1 \%$ to $39.8 \%$ ) in three of seven studies that reported the rate of delayed surgery. The major reasons for delayed surgery in the LA group were unsatisfactory results in-

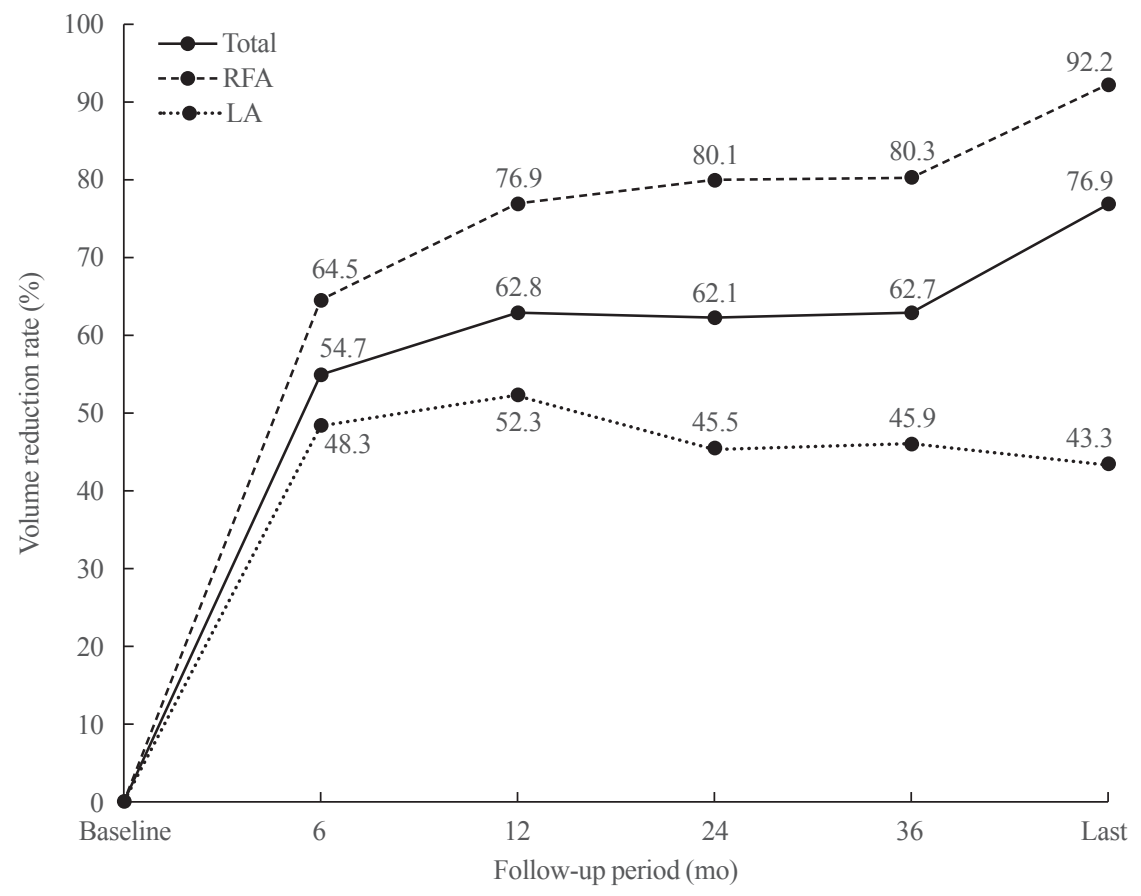

Fig. 2. The trends of pooled volume reduction rates for ablated nodules in the total subjects, total, and separately for the radiofrequency ablation (RFA) and laser ablation (LA) groups.

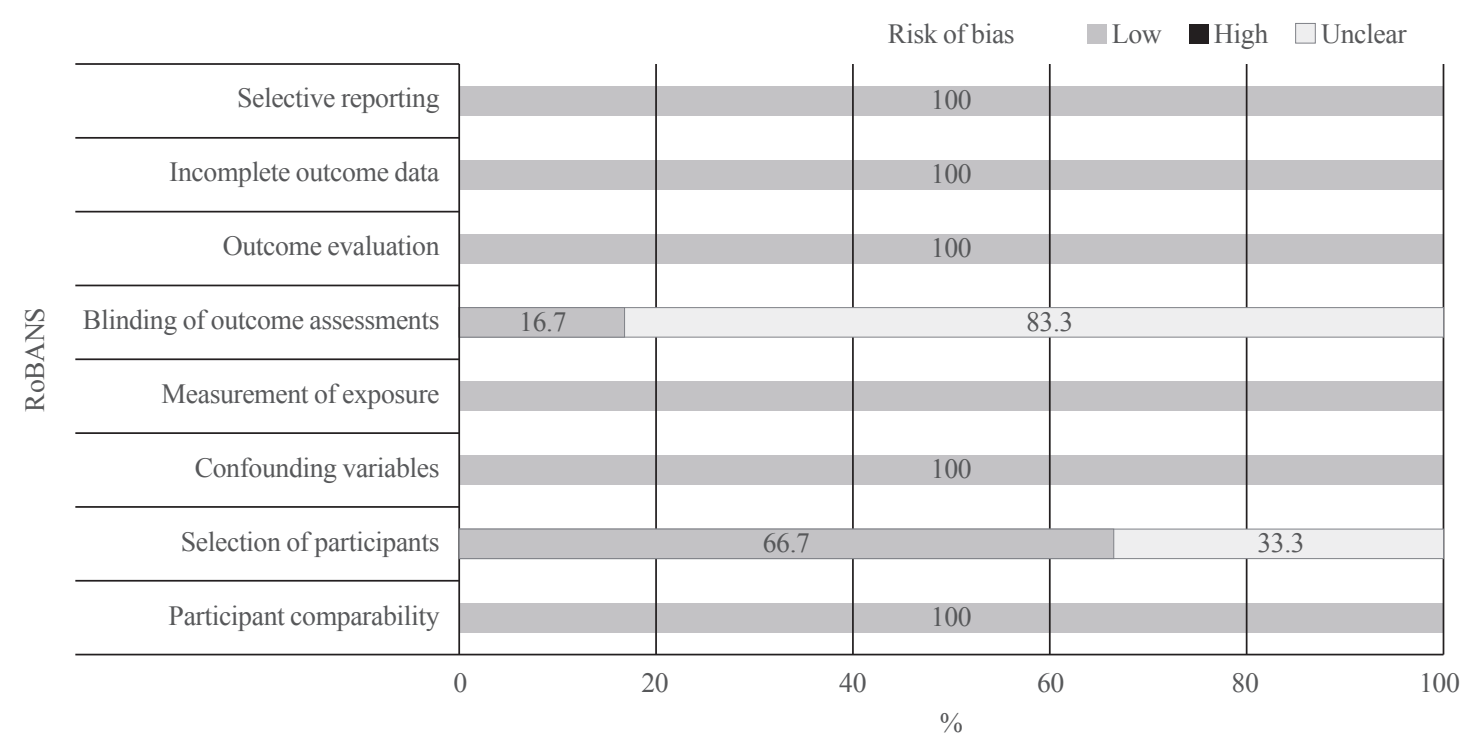

Fig. 3. Quality assessment of the included studies according to risk of bias for nonrandomized studies (RoBANS). 
cluding regrowth, the persistence of cosmetic concerns, or compressive symptoms. The detailed number and etiologies of these are described in Supplemental Table S1.

\section{Quality assessment of the studies}

The quality of the included studies was assessed according to the RoBANS criteria, and the results are presented in Fig. 3. All 12 studies had a low risk of bias in selective reporting, incomplete outcome data, outcome data, measurement of exposure, confounding variables, and participant comparability domains. However, four of the 12 studies were considered to have an unclear risk of bias in the selection of participants, as they made size criteria into inclusion criteria $[4,8,9,13]$. In addition, ten of the 12 studies showed an unclear risk of bias in blinding to the outcome of the assessment domain because they did not clearly report patient/investigator blinding [3,6-14].

\section{DISCUSSION}

The current systematic review and meta-analysis presents longterm follow-up results of more than 3 years for thermal ablation for the treatment of benign thyroid nodules. The trends in VRR for the ablated nodules showed rapid volume reduction at 12-month follow-up, a plateau from 12 to 36 months, and further volume reduction occurring after 36 months, demonstrating the long-term maintenance of treatment efficacy. The complication rate for thermal ablation was an acceptable 3.8\%. Moreover, the patients showed no unexpected delayed complications during the follow-up period. Therefore, long-term follow-up analysis showed thermal ablation by RFA or LA to be an effective and safe method for treating benign thyroid nodules.

However, the subgroup analysis showed different results for the two ablation methods of RFA and LA, which are the main ablation options for treating benign thyroid nodules [3-14]. In terms of volume reduction, RFA showed a gradual increment in VRR to $92.2 \%$ at the last follow-up, whereas LA showed a rapid volume reduction up to 12 months, but then a plateau or gradual slight decrease afterwards. In terms of delayed surgery during the follow-up period, no patient was recorded as undergoing delayed surgery in the RFA group, whereas the pooled proportion of patients who underwent delayed surgery was $21.4 \%$ in the LA group. The decrease in VRR after 12 months and the substantial proportion of patients who underwent delayed surgery in the LA group suggest substantial regrowth of nodules following LA. In terms of safety, the complication rate was acceptable in both groups $(4.6 \%$ in the RFA group and $2.4 \%$ in the LA group), and the major complication rate was lower in the RFA group (1.3\%) than in the LA group (1.8\%). These results are similar to those of a previous meta-analysis comparing the short-term results (6 to 12 months) of RFA and LA [15]; for the treatment of benign thyroid nodules, both the previous shortterm and the current long-term meta-analyses indicate the superior efficacy of RFA in comparison with LA [15].

Ultrasound-guided thermal ablations rapidly became the main strategy for treating benign thyroid nodules, solving cosmetic problems and compressive symptoms [1,2]. Therefore, a clinical outcome such as volume reduction can be used as a scale to assess the efficacy of the different methods [35]. Although thermal ablation has shown favorable efficacy [3-14], several studies reported that results may differ according to the follow-up period $[9,13]$. In addition, a few studies with long follow-up periods showed regrowth of treated nodules 2 to 3 years after ablation $[6,8,9,13,14]$. To clarify the rate of regrowth, long-term analysis of a period of more than 2 to 3 years is required. Although a previous meta-analysis using short-term results (6 to 12 months) demonstrated no regrowth [15], our long-term metaanalysis of more than 3 years of follow-up demonstrated a number of treated benign nodules showing regrowth during followup period, as reflected by the long-term changes in VRR and the requirement for delayed surgery.

Several factors have been suggested for determining the effectiveness of treatments for benign thyroid nodules, including change in the mean volume of the index nodule, the proportion of the solid component, and the multiplicity of treatment sessions $[9,13,15,36,37]$. Other factors could be the ablation method and the completion of margin ablation to avoid marginal regrowth [38]. First, as RFA generally uses the moving-shot technique, the ablation of the entire nodular margins can be maximized $[13,36,39]$. The moving electrode can target the marginal vessels and minimize the heat-sink effect by ablating these vessels; this is especially effective in hypervascular nodules [39]. By contrast, the initial LA studies usually involved placing the laser delivery fiber into the center of the nodule during the ablation, which could lead to incomplete ablation of the nodule margin [9]. Second, the modified straight-type internally cooled electrodes used for RFA are easily manageable when performing the moving-shot technique because of the short $(7 \mathrm{~cm})$ and thin $(18 \mathrm{G})$ hardware $[18,40]$. In addition, internally cooled electrodes allow a more overt ablation volume by minimizing carbonization [15]. By contrast, in LA, the 300 to $400 \mu \mathrm{m}$ diameter plane-cut optic fiber passing through the sheath of a $21 \mathrm{G}$ needle with 5 to $10 \mathrm{~mm}$ of bare fiber is relatively difficult to 
control compared with the single electrode used in RFA. Third, the size of the active tip $(0.5,1.0,1.5$, or $2.0 \mathrm{~cm})$ used in RFA can be selected according to nodule size. Although updates to the LA strategy, such as multiple fibers and pull-back techniques, may expand the ablated volume, the maneuverability is still lower than that in RFA.

There are a number of limitations to the current study. First, only a relatively small number of relevant studies with followup data of more than 3 years have been published, and the pooled data are based on this low number of studies. Second, the size of the cohorts of the included studies varied. Third, although the overall inclusion criteria were similar, the detailed criteria were not identical across the studies. Despite all these limitations, this systematic review and meta-analysis reveals comparative long-term data on the efficacy of RFA and LA for treating benign thyroid nodules.

In conclusion, this systematic review found that long-term follow-up analysis of more than 3 years showed thermal ablations to be safe and effective methods for treating benign thyroid nodules. In addition, according to the VRR, RFA was superior to LA for treating benign thyroid nodules, with less regrowth and less delayed surgery. We suggest technical differences and completion of margin ablation as explanatory factors for the differences in clinical outcomes between the two ablation groups.

\section{CONFLICTS OF INTEREST}

None, except Jung Hwan Baek. Financial activities related to the present article: none to disclose. Financial activities not related to the present article: patent holder of unidirectional ablation electrode. Other relationships: Consultant of two radiofrequency companies, STARmed and RF medical since 2017.

\section{AUTHOR CONTRIBUTION}

Conception or design: S.J.C., J.H.B. Acquisition, analysis, or interpretation of data: S.J.C., J.H.B. Drafting the work or revising: S.J.C., J.H.B., S.R.C., Y.J.C., J.H.L. Final approval of the manuscript: J.H.B.

\section{ORCID}

Se Jin Cho https://orcid.org/0000-0001-6450-7554

Jung Hwan Baek https://orcid.org/0000-0003-0480-4754

\section{REFERENCES}

1. Pacella CM, Bizzarri G, Guglielmi R, Anelli V, Bianchini A, Crescenzi A, et al. Thyroid tissue: US-guided percutaneous interstitial laser ablation: a feasibility study. Radiology 2000; 217:673-7.

2. Jeong WK, Baek JH, Rhim H, Kim YS, Kwak MS, Jeong HJ, et al. Radiofrequency ablation of benign thyroid nodules: safety and imaging follow-up in 236 patients. Eur Radiol 2008; 18:1244-50.

3. Dossing H, Bennedbaek FN, Hegedus L. Long-term outcome following interstitial laser photocoagulation of benign cold thyroid nodules. Eur J Endocrinol 2011;165:123-8.

4. Gambelunghe G, Fede R, Bini V, Monacelli M, Avenia N, D'Ajello M, et al. Ultrasound-guided interstitial laser ablation for thyroid nodules is effective only at high total amounts of energy: results from a three-year pilot study. Surg Innov 2013;20:345-50.

5. Gambelunghe G, Stefanetti E, Colella R, Monacelli M, Avenia N, De Feo P. A single session of laser ablation for toxic thyroid nodules: three-year follow-up results. Int J Hyperthermia 2018;34:631-5.

6. Magri F, Chytiris S, Molteni M, Croce L, Coperchini F, Rotondi $\mathrm{M}$, et al. Laser photocoagulation therapy for thyroid nodules: long-term outcome and predictors of efficacy. J Endocrinol Invest 2020;43:95-100.

7. Negro R, Greco G. Unfavorable outcomes in solid and spongiform thyroid nodules treated with laser ablation: a 5-year follow-up retrospective study. Endocr Metab Immune Disord Drug Targets 2019;19:1041-5.

8. Papini E, Rago T, Gambelunghe G, Valcavi R, Bizzarri G, Vitti P, et al. Long-term efficacy of ultrasound-guided laser ablation for benign solid thyroid nodules: results of a threeyear multicenter prospective randomized trial. J Clin Endocrinol Metab 2014;99:3653-9.

9. Valcavi R, Riganti F, Bertani A, Formisano D, Pacella CM. Percutaneous laser ablation of cold benign thyroid nodules: a 3-year follow-up study in 122 patients. Thyroid 2010;20: 1253-61.

10. Aldea Martinez J, Aldea Viana L, Lopez Martinez JL, Ruiz Perez E. Radiofrequency ablation of thyroid nodules: a long-term prospective study of 24 patients. J Vasc Interv Radiol 2019;30:1567-73.

11. Deandrea M, Trimboli P, Garino F, Mormile A, Magliona G, Ramunni MJ, et al. Long-term efficacy of a single session of RFA for benign thyroid nodules: a longitudinal 5-year obser- 
vational study. J Clin Endocrinol Metab 2019;104:3751-6.

12. Jung SL, Baek JH, Lee JH, Shong YK, Sung JY, Kim KS, et al. Efficacy and safety of radiofrequency ablation for benign thyroid nodules: a prospective multicenter study. Korean J Radiol 2018;19:167-74.

13. Lim HK, Lee JH, Ha EJ, Sung JY, Kim JK, Baek JH. Radiofrequency ablation of benign non-functioning thyroid nodules: 4-year follow-up results for 111 patients. Eur Radiol 2013;23:1044-9.

14. Sim JS, Baek JH, Lee J, Cho W, Jung SI. Radiofrequency ablation of benign thyroid nodules: depicting early sign of regrowth by calculating vital volume. Int J Hyperthermia 2017;33:905-10.

15. Ha EJ, Baek JH, Kim KW, Pyo J, Lee JH, Baek SH, et al. Comparative efficacy of radiofrequency and laser ablation for the treatment of benign thyroid nodules: systematic review including traditional pooling and bayesian network meta-analysis. J Clin Endocrinol Metab 2015;100:1903-11.

16. Liberati A, Altman DG, Tetzlaff J, Mulrow C, Gotzsche PC, Ioannidis JP, et al. The PRISMA statement for reporting systematic reviews and meta-analyses of studies that evaluate health care interventions: explanation and elaboration. Ann Intern Med 2009;151:W65-94.

17. Ha EJ, Lim HK, Yoon JH, Baek JH, Do KH, Choi M, et al. Primary imaging test and appropriate biopsy methods for thyroid nodules: guidelines by Korean Society of Radiology and National Evidence-Based Healthcare Collaborating Agency. Korean J Radiol 2018;19:623-31.

18. Kim JH, Baek JH, Lim HK, Ahn HS, Baek SM, Choi YJ, et al. 2017 Thyroid radiofrequency ablation guideline: Korean Society of Thyroid Radiology. Korean J Radiol 2018;19:63255 .

19. Baek JH, Kim YS, Lee D, Huh JY, Lee JH. Benign predominantly solid thyroid nodules: prospective study of efficacy of sonographically guided radiofrequency ablation versus control condition. AJR Am J Roentgenol 2010;194:1137-42.

20. Ahmed M, Solbiati L, Brace CL, Breen DJ, Callstrom MR, Charboneau JW, et al. Image-guided tumor ablation: standardization of terminology and reporting criteria: a 10-year update. J Vasc Interv Radiol 2014;25:1691-705.

21. Baek JH, Lee JH, Sung JY, Bae JI, Kim KT, Sim J, et al. Complications encountered in the treatment of benign thyroid nodules with US-guided radiofrequency ablation: a multicenter study. Radiology 2012;262:335-42.

22. Kim C, Lee JH, Choi YJ, Kim WB, Sung TY, Baek JH. Complications encountered in ultrasonography-guided ra- diofrequency ablation of benign thyroid nodules and recurrent thyroid cancers. Eur Radiol 2017;27:3128-37.

23. Kim SY, Park JE, Lee YJ, Seo HJ, Sheen SS, Hahn S, et al. Testing a tool for assessing the risk of bias for nonrandomized studies showed moderate reliability and promising validity. J Clin Epidemiol 2013;66:408-14.

24. Kim KW, Lee J, Choi SH, Huh J, Park SH. Systematic review and meta-analysis of studies evaluating diagnostic test accuracy: a practical review for clinical researchers: part I. general guidance and tips. Korean J Radiol 2015;16:1175-87.

25. Lee J, Kim KW, Choi SH, Huh J, Park SH. Systematic review and meta-analysis of studies evaluating diagnostic test accuracy: a practical review for clinical researchers: part II. Statistical methods of meta-analysis. Korean J Radiol 2015; 16:1188-96.

26. Suh CH, Park SH. Successful publication of systematic review and meta-analysis of studies evaluating diagnostic test accuracy. Korean J Radiol 2016;17:5-6.

27. Higgins JP, Thompson SG, Deeks JJ, Altman DG. Measuring inconsistency in meta-analyses. BMJ 2003;327:557-60.

28. Piana S, Riganti F, Froio E, Andrioli M, Pacella CM, Valcavi R. Pathological findings of thyroid nodules after percutaneous laser ablation : a series of 22 cases with cyto-histological correlation. Endocr Pathol 2012;23:94-100.

29. Spiezia S, Garberoglio R, Milone F, Ramundo V, Caiazzo C, Assanti AP, et al. Thyroid nodules and related symptoms are stably controlled two years after radiofrequency thermal ablation. Thyroid 2009;19:219-25.

30. Sung JY, Kim YS, Choi H, Lee JH, Baek JH. Optimum firstline treatment technique for benign cystic thyroid nodules: ethanol ablation or radiofrequency ablation? AJR Am J Roentgenol 2011;196:W210-4.

31. Valcavi R, Tsamatropoulos P. Health-related quality of life after percutaneous radiofrequency ablation of cold, solid, benign thyroid nodules: a 2-year follow-up study in 40 patients. Endocr Pract 2015;21:887-96.

32. Deandrea M, Sung JY, Limone P, Mormile A, Garino F, Ragazzoni F, et al. Efficacy and safety of radiofrequency ablation versus observation for nonfunctioning benign thyroid nodules: a randomized controlled international collaborative trial. Thyroid 2015;25:890-6.

33. Negro R, Salem TM, Greco G. Laser ablation is more effective for spongiform than solid thyroid nodules: a 4-year retrospective follow-up study. Int J Hyperthermia 2016;32:8228.

34. Hong MJ, Sung JY, Baek JH, Je MS, Choi DW, Yoo H, et al. 
Safety and efficacy of radiofrequency ablation for nonfunctioning benign thyroid nodules in children and adolescents in 14 patients over a 10-year period. J Vasc Interv Radiol 2019;30:900-6.

35. Papini E, Guglielmi R, Bizzarri G, Graziano F, Bianchini A, Brufani $\mathrm{C}$, et al. Treatment of benign cold thyroid nodules: a randomized clinical trial of percutaneous laser ablation versus levothyroxine therapy or follow-up. Thyroid 2007;17: 229-35.

36. Huh JY, Baek JH, Choi H, Kim JK, Lee JH. Symptomatic benign thyroid nodules: efficacy of additional radiofrequency ablation treatment session: prospective randomized study. Radiology 2012;263:909-16.

37. Dossing H, Bennedbaek FN, Hegedus L. Effect of ultra- sound-guided interstitial laser photocoagulation on benign solitary solid cold thyroid nodules: one versus three treatments. Thyroid 2006;16:763-8.

38. Sim JS, Baek JH. Long-term outcomes following thermal ablation of benign thyroid nodules as an alternative to surgery: the importance of controlling regrowth. Endocrinol Metab (Seoul) 2019;34:117-23.

39. Baek JH, Lee JH, Valcavi R, Pacella CM, Rhim H, Na DG. Thermal ablation for benign thyroid nodules: radiofrequency and laser. Korean J Radiol 2011;12:525-40.

40. Lim HK, Baek JH, Lee JH, Kim WB, Kim TY, Shong YK, et al. Efficacy and safety of radiofrequency ablation for treating locoregional recurrence from papillary thyroid cancer. Eur Radiol 2015;25:163-70. 